\title{
ALGUMAS CONSIDERAÇÕES SOBRE O ESTATUTO DO PSICOLÓGICO NO "PROJETO"1 FREUDIANO
}

Carmen Beatriz MILIDONI²

- RESUMO: Embora no "Projeto" freudiano não seja oferecida, de uma maneira explícita, uma conceituação a respeito do estatuto do psicológico, pensamos que é possivel delinear esse estatuto e tentaremos fazê-lo com base em uma maneira de interpretar o modelo do psiquismo que é construído no texto freudiano. Isto levar-nos-á também a situar o "Projeto" em relação ao clássico problema mente-corpo. Pretendemos dar conta da tarefa proposta apoiando-nos, sobretudo, em uma distinção que estabeleceremos entre o representar, entendido como ato intencional, e a representação, entendida como traço de memória. Também contemplaremos a forma de comportamento do fator quantitativoenergético nas ordens processuais do psicológico e do neurofisiológico.

- PALAVRAS-CHAVE: Neurônios; quantidade; fluência; traço mnésico; representação; intencionalidade; identidade funcional.

\section{Introdução}

É coisa sabida, para os leitores de Freud, que este manteve sempre uma atitude agnóstica quanto à possibilidade de desvendar a natureza do que fosse propriamente "o psíquico". Em "Algumas lições elementares de psicanálise", obra tardia (1940 [1938]), coloca-se a seguinte tese: não conhecemos efetivamente a natureza do psíquico, senão apenas aquilo que é psíquico, isto é, um conjunto de fenômenos, tais como percepções, idéias etc., e as leis que regem esses fenômenos, das quais se pode fazer um uso prático. E, para o fundador da Psicanálise, isto ocorre em toda ciência da natureza - incluindo a psicologia -, e provisoriamente satisfaz, mesmo que se tenha consciência da ignorância daquilo que seguramente é "o mais importante", qual seja, a natureza dos fenômenos (Freud, 1964, v. XXIII, p. 282-3).

1. Abreviatura que usaremos para nos referirmos à obra freudiana "Entwurf einer Psychologie".

2. Professora do Departamento de Filosofia da Faculdade de Filosofia, Ciências e Letras - UNESP - 17525-900 Marilia - SP. 
Malgrado esta limitação de princípio, o gênio de Freud evidenciou-se ao tratar "daquilo que é psíquico", indo muito além do meramente fenomênico, isto é, fazendo uso de conceitos e de hipóteses de teor especulativo ou do nível do metapsicológico, ${ }^{3}$ o que lhe permitira desvendar os enigmas que estavam embutidos no material fenomênico que se lhe oferecia e ver a mente humana e seu funcionamento sob uma nova luz. ${ }^{4}$

Mas uma coisa é a especulação psicanalítica, e outra coisa é a especulação filosófica, e o considerar as hipóteses metapsicológicas enquanto possuidoras de um valor fundamentalmente operacional e não-fundante com relação a uma dada ordem de processos constitui um fato marcante da epistemologia freudiana. ${ }^{5}$ As hipóteses metapsicológicas não dizem respeito à natureza do psíquico, nem lhe traçam as coordenadas transcendentais, embora possam repousar sobre pressupostos filosóficos e constituam, às vezes, bons pontos de partida para se extraírem, das mesmas, conseqüências que sejam, sim, filosóficas. Nada impede, portanto, focalizar com olhar filosófico algo não-filosófico, neste caso, as construções metapsicológicas. E isto é o que tentaremos fazer com relação ao "Projeto" freudiano de 1895, um manuscrito pré-psicanalítico que o editor inglês rebatizara com o nome de "Projeto para uma psicologia científica" (Freud, 1966, v. I), e cujo primeiro batismo correra por conta de sua primeira edição em alemão como "Entwurf einer Psychologie" "Projeto para uma psicologia") (Freud, 1950).

Nossa questão é a seguinte: será que nesse texto podemos encontrar algumas pistas que esclareçam algo a respeito da natureza do psíquico?

Propomo-nos a realizar aqui essa investigação, circunscrevendo-nos à consideração do modelo de psiquismo que o "Projeto" fornece e fazendo dos componentes básicos que o integram $\circ$ objeto central de nossa análise.

Consideremos o trecho inaugural do "Projeto" que serve de "Introdução" à sua Parte I ou "Plano Geral":

A finalidade deste projeto é fornecer uma psicologia científico-naturalista: isto é, apresentar os processos psiquicos como estados quantitativamente determinados de partículas materiais especificáveis, tornando assim esses processos claros e livres de contradição. Há duas idéias principais em jogo: [1] Conceber aquilo que distingue a atividade do repouso como Q, sujeita às leis gerais do movimento. [2] Supor como partículas materiais os neurônios.

3. Nível esse correspondente à "Metapsicologia", aquela dimensão da Psicanálise que, segundo Freud, teria por função elaborar as ferramentas teóricas (conceitos, princípios, modelos) que serviriam de base de sustentação para hipóteses de menor grau de teoreticidade, isto é, para aquelas hipóteses cuja relação com o material fenomênico seria bem mais próxima. Caberia às construções metapsicológicas a missão última de conferir um máximo grau da inteligibilidade a esse material fenomênico. Contudo, tais construções não teriam provindo desse material; elas "impor-se-iam" antes a este, e o fariam, a príncipio, com o valor de "convenções". Todavia, o caráter arbitrário destas "convenções" deverá ser descartado, já que as mesmas manteriam relações significativas com o material empírico. Ver, a esse respeito, Freud, 1967, v. XIV, p. 169.

4. Pense-se, sobretudo, na descoberta da determinação do sentido de qualquer ato humano a partir do inconsciente.

5. Dado o teor convencional dos conceitos que fazem parte das hipóteses metapsicológicas. 
"N e Qn" - Hoje em dia parecidos ensaios são freqüentes. (Freud, 1966, v. I, p. 395; 1950, p. 305)

Comentando este trecho, diremos que o "Projeto" tinha como meta oferecer um certo modelo de psicologia científica via a apresentação dos processos psíquicos na qualidade de estados quantitativamente determinados de partículas materiais especificadas como neurônios. Este tipo de apresentação teria como finalidade tornar esses processos "claros e livres de contradição". Ora, parece ser que dependendo do sentido e alcances que o "Projeto" possa ter dado ao estatuto dessa especial "apresentação", os processos psíquicos identificar-se-ão (fundir-se-ão) com esses estados, e então o psicológico não será em essência algo distinto do neuronal, algo assim como uma província ontológica diferenciada, ou bem esses processos terão nesses estados meros veículos de exibição e serão tratados, por mera vontade metodológica, como se fossem tais veículos.

No primeiro dos casos, haveria um reducionismo naturalista, de cunho comteano (Comte, 1975, Lições 2 e 45), e a especificidade do psicológico ficaria comprometida, mas de qualquer maneira ter-se-ia ousado em teorizar acerca da natureza do psicológico.

No segundo dos casos, tendo a apresentação em questão um valor puramente analógico, as conseqüências inverter-se-iam: o psicológico conservaria um estatuto próprio, mas, em contrapartida, poucas chances haveria de se penetrar na sua essência.

De qualquer forma, e seguindo nisto a inspiração de Searle, pensamos que pouco adiantaria elucidar se estamos aqui diante de uma alternativa monista ou dualista, que se colocaria, diante do clássico problema da relação mente-corpo ou, no caso, da relação psíquico-neuronal, em termos excludentes (Searle, 1987, p. 19).

Pensamos que a "apresentação" do "Projeto" saberá escapar a esses dilemas. E, embora no manuscrito não se teorize de modo explícito acerca da natureza do psíquico, será possível extrair, via uma interpretação das hipóteses e estratégias de construção que estão na base da "apresentação" em causa, conseqüências que permitirão delinear o estatuto do psicológico à luz de certos traços vistos como essenciais.

\section{O modelo do psiquismo no "Projeto"}

Como expediente metodológico encarregado de veicular a mencionada "apresentação", o "Projeto" valer-se-á de um modelo que adotará a forma de um sistema neurônico, o sistema " $\varphi \Psi \omega$ ", em que cada letra grega designará um sub-sistema ao qual estará associada uma função psíquica correlata. Assim, as funções da sensação, da memória, e da percepção-consciência corresponderão aos sistemas (ou sub-sistemas) " $\varphi$ ", " $\Psi$ " e $\omega$ ", respectivamente. Pelo sistema " $\varphi \Psi \omega$ " circulará uma certa quantidade, e ele será chamado de "aparelho" (Freud, 1966, v. I, p. 312; 1950, p. 321), realçando-se, por esta denominação, seu aspecto funcional. 
Cabe agora a pergunta: de que maneira o modelo proposto irá dar conta da "apresentação" que está em jogo no "Projeto"? Para adiantar uma primeira resposta, achamos que será suficiente apontarmos, de maneira sucinta, nosso ponto de vista no que tange ao estatuto epistemológico do modelo em apreço. Esse ponto de vista repousa fundamentalmente em algumas conceituações acerca de modelos e de metáforas, que foram desenvolvidas por M. Black ao longo dos artigos "A metáfora" (1966a), e "Modelos e arquétipos" (1966b).

Nos interessarão aqui dois tipos de recursos modelísticos explorados por Black (1966a, p. 48-56): as metáforas de tipo interativo, que apesar do seu uso em contextos literários podem chegar a ter relevância epistemológica; e os que Black chama de "modelos teóricos", de uso comum na ciência, mas restringindo-nos, no entanto, ao caso em que os ditos modelos, longe de serem vistos como meras ficções heurísticas, são antes empregados com uma certa vocação realística. ${ }^{6}$

É preciso advertirmos, todavia, que a maneira com que iremos tratar esta questão de modelos e metáforas, conforme o pensamento de Black, é fruto de articulações que temos estabelecido com base em conceitos que estão disseminados nos trabalhos do autor mencionados acima; é por esta razão que será dispensada a referência aos textos de maneira pontual.

Diremos, pois, que tanto em uma metáfora de tipo interativo, como também em um modelo teónico (quando se faz do mesmo um uso não-fictício) haveria algo assim como uma assimilação, veiculada através do domínio que é próprio do modelo, entre o domínio que se quer explorar ou conhecer melhor (domínio original ou primário) e o domínio do qual esse modelo tirou as suas "entidades" (domínio secundário), que é um domínio em certo sentido familiar.

Sustentaremos que, de modo semelhante, o modelo construído no "Projeto" teria promovido um certo tipo de assimilação, via o domínio que lhe é próprio (o do quantitativo-neuronal) entre o domínio dos processos psicológicos (domínio original ou primário) e uma espécie de duplo domínio secundário constituído pelo domínio do propriamente neuronal, mais o domínio do psicopatológico, como veremos.

Resta frisar ainda que se trata de uma assimilação baseada em algum tipo de semelhança (preexistente ou mesmo criada) entre os domínios postos em correlação, assimilação essa que, ao trabalhar pela via da semelhança, incluirá identidades e também diferenças.

\section{A matéria prima do modelo}

Consideremos agora mais de perto a ontologia do modelo em questão, e a forma pela qual nós pensamos que ela foi derivada do domínio ou domínios secundários

6. Estamos expondo de maneira muito condensada o pensamento de M. Black; este assunto ficará mais claro na última seção do presente artigo. 
acima assinalados. Tomando como ponto de partida o trecho introdutório do "Projeto" que citamos no início deste artigo, podemos inferir que as "entidades" que integram o domínio do modelo são as seguintes: a) neurônios; b) quantidades (ou algo da ordem do quantitativo que determina os diversos estados dos neurônios). Também no mesmo trecho introdutório avança-se o que pode ser visto como configurando a linguagem que seria a "linguagem do modelo". São assim consignados dois termos básicos, "N" e "On" ou "Q". 7 Mas deve-se fazer a ressalva de que essas expressões não são abreviaturas que simplesmente denominam as entidades que fazem parte do modelo; elas devem ser vistas antes como termos teóricos que servem para condensar (nomeando também) pontos de vista metapsicológicos acerca daquelas entidades. Para entender o que isto significa, será preciso prestarmos atenção aos domínios dos quais foram tirados os elementos "neurônio" e "quantidade", e às estratégias de derivação dos mesmos que foram empregadas. ${ }^{8}$

Vejamos primeiramente o caso do elemento "quantidade", e partamos daquilo que é chamado, na primeira seção da Parte I do texto do "Projeto", de "A concepção quantitativa", e que aparece na qualidade de "Primeiro Teorema Principal":

Deriva-se diretamente de observações clinico-patológicas, sobretudo das relativas a representações excessivamente intensas - na histeria e nas obsessões, nas quais, como veremos, a característica quantitativa surge com mais clareza do que seria normal. Processos como a estimulação, substituição, conversão e descarga, que tiveram de ser descritos ali (em conexão com esses distúrbios), sugerem diretamente a concepção da excitação neuronal como quantidade em estado fluente. Não parecia ilícito tentar generalizar o que se comprovou ali. (Freud 1966, v. I, p. 295-6; 1950, p. 305).

Este trecho contém vários pontos que merecem ser analisados:

1. A "concepção" em questão está dizendo respeito, de maneira explícita, aos neurônios (ou melhor, à "excitação neuronal"). E o "Primeiro Teorema Principal" postula a concepção dessa excitação como "quantidade em estado fluente". A "quantidade" é, portanto, da natureza da "excitação neuronal", e a "fluência" é seu principal atributo.

2. A concepção quantitativa "deriva-se de observações cliníco-patológicas": temos aqui uma indicação de um dos domínios do qual o modelo foi extraído, qual seja, o domínio do psicopatológico (entendido, claro está, tanto no nível dos processos dessa ordem, quanto no nível de sua exploração e terapia).

7. Baseando-se em um exame dos contextos em que tais símbolos são usados no "Projeto", o tradutor inglês Strachey caracterizará "O" como simbolizando "a quantidade (em geral, ou da ordem de magnitude do mundo exterior)"; por sua vez, "On" fará referência "à quantidade (da ordem de magnitude intercelular)". Ver Freud, 1966, v. I, p. 294. De fato, isto funciona assim ao longo do texto, embora Freud nem sempre permaneça fiel a essa distinção.

8. Algumas das idéias principais que serão expostas a esse respeito encontram-se também em Milidoni, 1993. cap. 2. 
3. Na "concepção da excitação neuronal como quantidade em estado fluente", há a transposição de uma "característica quantitativa" exibida por "representações" para o âmbito da "excitação neuronal".

Poderíamos indagar: qual é a operação que está na base dessa transposição, que bem poderia ter o caráter de uma operação de derivação "metáforo-metonímica" à la Laplanche? ${ }^{9}$

Qualquer que seja a resposta, ela só poderá surgir da elucidação daquele elemento que é o resultado da mencionada transposição, qual seja: "quantidade em estado fluente". Com efeito, Freud (1955a, v. III) tinha assinalado, em sua obra: "As neuropsicoses de defesa", um fato surpreendente que acontecia em relação aos dois elementos básicos que eram considerados componentes de qualquer fenômeno psíquico, quais sejam, "representação"e "afeto". ${ }^{10}$ A tese principal que se assentava nesse artigo era a de que existiria, na origem de certos processos patológicos notoriamente a histeria e a neurose obsessiva -, a deflagração de um processo defensivo, o qual consistiria em se dissociar, de representações que em si mesmas eram de natureza penosa, quase que invariavelmente de conteúdo sexual, e tidas como incompatíveis pelo sujeito, o que seria sua "soma de excitação" ou "afeto". Uma vez operada essa dissociação, os elementos "representação" e "afeto" iriam sofrer vicissitudes próprias (Freud, 1955a, v. III, p. 47-9).

Em Freud: o movimento de um pensamento, Monzani (1989, p. 91) diz: "A grande descoberta da Psicanálise foi perceber que não há relação intrínseca entre representação e afeto e que, ao contrário, essa relação é de uma pura soldagem entre uma e outro, de sorte que são passíveis de se dissociarem e tomarem rumos distintos." E - continuará o autor - embora Ricoeur tenha razão ao afirmar que o afeto é sempre afeto de uma representação, isto não nos deve fazer esquecer que, uma vez produzida a dissociação entre representação e afeto, "a trajetória desse afeto nem sempre acabará numa ligação com uma representação, como é o caso do puro ataque de angústia". (1989, p. 92). Caso este em que - sempre segundo Monzani - o afeto revelaria sua característica fundamental, qual seja, "a de ser um quantum energético" (1989, p. 92).

Pensamos que é sobretudo desse afeto que, separado das representações, circula a caminho de diferentes destinos (conversão somática, deslocamento, transformação),

9. Estamos nos referindo a um modo de derivação de conceitos especificamente psicanalíticos postulado por Laplanche e que subentende duas operações de derivação, a "metafórica" e a "metonímica". Por "derivação metafórica" de um conceito devemos entender a "transposição, por semelhança, e para um campo separado mas estruturado como análogo", de um certo elemento pertencente a outro campo teórico ou conceitual; no caso da "derivação metonímica" teriamos uma "extensão por continuidade, na passagem insensivel de um campo para outro campo conexo", do elemento de ponto de partida. Ver Laplanche, 1970, p. 202-3.

10. É comum, entre os estudiosos do pensamento de Freud, remontar a maneira de este abordar os fenômenos psíquicos em termos de dois elementos, "representação" e "afeto", à influência de F. Brentano, que fora mestre de filosofia do próprio Freud. Assim, para R. Wollheim - para citar um exemplo - tal perspectiva de abordagem "foi o pressuposto filosófico subjacente que Freud reteve ao longo de toda sua obra e que, provavelmente, deriva do filósofo vienense Franz Brentano". Ver Wollheim, s.d., p. 36. 
que surgirá a idéia de uma "quantidade em estado fluente". Mas consignemos, como elemento complementar desta hipótese, o seguinte trecho:

Nas funções psiquicas, há razão para distinguir alguma coisa (quantum de afeto, soma de excitação) que possui todas as características de uma quantidade (embora não se possuam os meios para medi-la); que é capaz de aumento, diminuição, deslocamento e descarga, e que se espalha sobre os traços-mnésicos das representações mais ou menos como uma carga elétrica o faz sobre a superfície de um corpo. (Freud, 1955a, v. III, p. 60)

Façamos uma breve digressão para atendermos a algumas considerações que são tecidas por Green (1982, p. 17-20) em torno das expressões "afeto" e "quota de afeto". Aponta Green, em primeiro lugar, que a palavra "afeto" ("affect") é usada por Freud de maneira alternada com as expressões "Empfindung" e "Gefühl", cujas traduções são, respectivamente, "sensação, emoção" e "sentimento, emoção". Assim, conclui Green, "afeto" deve ser entendido como um termo categorial (metapsicológico e não-descritivo) que agrupa todos os aspectos subjetivos qualitativos da vida emocional em sentido amplo (emoções, sentimentos, paixões). Em segundo lugar, é preciso distinguir o significado da palavra "afeto" isoladamente, que remete para uma qualidade subjetiva, do significado da expressão "quota de afeto", que designa o aspecto propriamente econômico do fenômeno.

Das considerações precedentes é possível concluir que o afeto quantitativamente determinado ou "quantum de afeto", quando dissociado do componente representativo, tem a propriedade de ser deslocável, fluente, e que é essa propriedade do quantitativo (a fluência) o que se transpõe, no "Projeto", da ordem do psicopatológico para a ordem do neuronal.

À luz de tudo o que foi exposto, e voltando ao que temos chamado de "linguagem do modelo", vejamos qual seria a função de um dos seus termos básicos, qual seja, " $\mathrm{Q}$ ".

Por um lado, ele vai denotar uma quantidade, uma soma de excitação que circula pelos neurônios (e que, deste modo - poderíamos acrescentar - investe ou desinveste esses neurônios, atuando assim como um fator de diferenciação dos seus estados, que oscilariam entre o "cheio" e o "vazio").

Por outro lado, é preciso ter em conta o que o termo "Q" conota, isto é, o caráter fluente da excitação neuronal, como foi sugerido pelo comportamento de um quantum de afeto quando dissociado da representação. Neste sentido, pode-se aventurar que uma característica de um processo afetivo e, portanto, psicológico, ter-se-ia "colado" a processos neurônicos, de maneira que a quantidade denotada por " $\mathrm{Q}$ " carregaria um tanto de qualidade psíquica, por assim dizer.

Pensamos que é mais do que evidente que "Q" não é um termo descritivo mas teórico.

Consideremos agora o elemento "neurônio". O domínio do qual foi extraído esse elemento é o do neurológico, e isto é indicado na Seção 2 da Parte I do "Projeto", onde é introduzido um "Segundo Teorema Principal" com o título de "A Teoria dos Neurônios", teoria essa que contempla as principais descobertas histológicas da 
época. A idéia principal desta "teoria" é a de que o sistema nervoso compõe-se de neurônios que são distintos, porém homogêneos em sua estrutura (Freud, 1966, v. I, p. 297-8; 1950, p. 307); apesar desta homogeneidade estrutural, os neurônios apresentam-se dicotomicamente como sensoniais e motores, conforme recebam ou descarreguem quantidade (Freud, 1966, v. I, p. 296; 1950, p. 306). Tal homogeneidade implicará também uma importante conseqüência): ${ }^{11}$ a de que toda e qualquer diferença entre os neurônios não será morfológica mas ficará em última instância determinada por fatores outros, como o lugar ou a posição dos neurônios no sistema conforme o sub-sistema a que pertençam (diferença tópica); e por fatores quantitativos, como a forma em que se dá a passagem de quantidade entre esses neurônios, a grandeza e proveniência das quantidades em jogo etc. E as diversas funções psíquicas correlatas a esses neurônios estarão também diferenciadas por fatores desse tipo. Assim, pelos neurônios do sistema (ou sub-sistema) " $\varphi$ ", que ocupam uma posição periférica no sistema e estão ligados aos órgãos dos sentidos, o aparelho recebe os estímulos procedentes do mundo externo - cuja magnitude acredita-se não é muito pequena e isto na forma de impressões sensíveis. Mas competirá ao sistema " $\omega$ ", o de localização mais central e o que trabalha com quantidades ínfimas, tornar essas impressões sensíveis (uma espécie de in-put) em percepções conscientes. Isto porque a aparição da consciência, para o "Projeto", está correlacionada com uma máxima diminuição de quantidades, quase que com uma "volatilização" das mesmas. O sistema dos neurônios " $\Psi$ ", ou sistema mnemônico, que está situado entre " $\varphi$ " e " $\omega$ ", e no qual as quantidades em jogo são menores que a do sistema " $\varphi$ ", é o sistema em que fica registrada toda estimulação procedente de fora do sistema como um todo, e tudo o que se processa no sistema. Assim, as percepções que penetraram no sistema pela estimulação externa recebida por " $\varphi$ " ficarão registradas na forma de representações ou traços de memória (algo assim como "marcas" despojadas de toda qualidade sensível), em uma parte de " $\Psi$ " chamada " $\Psi$ do pallium". O fluir da "Q" que ativará esses traços se dará através de caminhos que ficaram fixados na rede neuronal, e isto pela repetida passagem das "Qs" excitatórias, procedentes de fora, ao longo dos neurônios " $\Psi$ ". Nesse traçado de caminhos, as "Qs" tiveram que vencer resistências a essa sua passagem. À "conductibilidade" dessas vias abertas desse modo, Freud chamou de "Bahnung", em nossa língua, "facilitação" (Freud, 1966, v. I, p. 298-301; 1950, p. 308-10). O conceito de "facilitação" permitirá definir a memória em termos das facilitações existentes entre os neurônios " $\Psi$ ", isto é, em termos de um conjunto de vias pelas quais a passagem de " $Q$ " encontra-se facilitada, e, dada a origem da " $Q$ " facilitante, teríamos na memória "a representação de todas as influências que ' $\Psi$ ' experimentou a partir do mundo externo" (Freud, 1966, v. I, p. 365; 1950, p. 364). Também em " $\Psi$ do pallium" ficará registrada a estimulação procedente do interior do corpo; neste caso, há uma via direta pela qual ascendem quantidades endógenas de

11. O ponto que se segue não é mais que um apanhado de algumas idéias expostas por Freud ao longo das seções 3 a 10 da Parte I do "Projeto". 
excitação. Tais quantidades irão se acumular em outra parte de " $\Psi$ ", mais próxima do interior do corpo, chamada " $\Psi$ do núcleo", erigindo-se em um fator de pressão (posto que elas procuram a descarga) e impulsionando, desta maneira, toda a atividade psíquica (Freud, 1966, v. I, p. 317; 1950, p. 325). Pelo fato de " $\Psi$ " ser o sistema que registra informações de tudo o que acontece (ou de ser o sistema da memória), os seus neurônios foram vistos por Freud enquanto possuidores de um estatuto especial: eles seriam, provavelmente, "os veículos dos processos psíquicos em geral" (Freud, 1966, v. I, p. 300; 1950, p. 309). Isto acarretaria a seguinte conseqüência: tudo o que acontecer fora de " $\Psi$ do pallium" adquirirá valor psíquico na medida em que aí for registrado. Cabe frisar ainda que se bem o elemento "neurônio" foi derivado de um contexto científico, o sistema " $\varphi / \Psi / \omega$ " que o "Projeto" construíra a partir dele foi fruto de uma montagem especulativa ou metapsicológica.

Voltando mais uma vez à "linguagem do modelo" e considerando o "Segundo Teorema Principal", temos de dizer que "N" (que junto com "Q" faz parte da "linguagem do modelo") designa partículas materiais especificadas como "neurônios", mas que, pelo fato de os "neurônios" do modelo terem sido retrabalhados metapsicologicamente, "N" não possuirá o estatuto de um termo descritivo ou empírico, ele terá antes o estatuto de um termo teórico, conforme antecipamos.

Se agora considerarmos "N" em relação com o "Primeiro Teorema Principal", uma conseqüência de insuspeitado alcance surgirá. Lembremos que tínhamos destacado, a respeito da aí assentada "concepção da excitação neuronal como quantidade em estado fluente", que na sua base havia a transposição de uma "característica quantitativa" exibida por "representações" para o âmbito da "excitação neuronal". Sustentaremos a hipótese de que nessa operação de transposição (colagem "metonímica", por assim dizer, metaforização?) junto com aquela "característica quantitativa" ter-se-ia "colado" também algum aspecto do elemento "representação" que presumimos pode ser definitório se encarado nos termos em que o assunto fora colocado por Brentano, o mestre de Freud em filosofia.

Em A psicologia do ponto de vista empínico, o psicólogo e filósofo Brentano sustenta a seguinte tese: "Os fenômenos psíquicos são representações ou repousam sobre representações" (1944, p. 94). Consideremos o que Brentano entende por "fenômenos psíquicos" e por "representações", destacando aqueles elementos que são interessantes para a nossa abordagem. No intuito de caracterizar os fenômenos psíquicos, Brentano começa por dividir o mundo de nossos fenômenos em duas classes, a dos fenômenos físicos e a dos fenômenos psíquicos (p. 92). Os fenômenos psíquicos podem-se definir, em uma primeira instância, negativamente, por contraposição aos fenômenos físicos como sendo fenômenos que não implicam nem extensão nem localização espacial (Brentano, 1944, p. 99). Mas o traço que os define positivamente é "o que os escolásticos medievais chamavam de presença intencional (ou ainda mental) de um objeto e que nós poderíamos chamar ... de referência a um contéudo, de direção a um objeto (que não é preciso entender como algo real), ou de objetividade imanente" (Brentano, 1944, p. 102). 
Conforme o conceito de representação que é formulado por Brentano, não se deve entender por representação aquilo que é representado, o objeto da representação, senão "o ato mesmo de representar" (p. 93). E - poderíamos acrescentar - na medida em que esse ato é um ato psíquico e definido como tal em termos do seu caráter intencional, isto é, pela sua referência a conteúdos ou pela sua direção a objetos, pode-se dizer, dentro desse marco conceitual, que o representar é um apontar virtual para algo.

Com base nestas considerações sustentaremos que, se devido à conexão de " $\mathrm{N}$ " com o "Segundo Teorema Principal" ele designa algo assim como um lugar físico (de natureza neuronal), será em virtude de sua conexão com o "Primeiro Teorema Principal" e pelo viés da "colagem" do elemento representacional que "N" designará algo assim como um lugar virtual, aquele que seria próprio do representar.

Portanto, a "ontologia neuronal" do modelo será uma ontologia de qualquer maneira mista, posto que o elemento "representação", já implícita, já explicitamente (ao ponto que, avançado já o texto do "Projeto", ele parecerá quase que substituir os neurônios) encontrar-se-á sempre "colado" ao elemento "neurônio".

Uma vez caracterizadas as "entidades" que fazem parte do modelo, passaremos a encará-lo em seu aspecto dinâmico; e para tanto introduziremos um novo componente que poderíamos chamar de princípio operacional desse modelo em virtude de ele ser indicador do seu modo de funcionamento. Tal princípio operacional ou princípio de inércia neurônica é o princípio da atividade neurônica em relação a "Q", e é enunciado da seguinte maneira: "Os neurônios tendem a se desfazer de Q" (Freud, 1966, v. I, p. 296; 1950, p. 305).

Todavia, esse princípio, que estrutura o sistema nos moldes de um simples "arco reflexo" (tudo o que entra no sistema, em termos quantitativo-energéticos ou quantitativos-excitatórios, sai, e o faz pela via de uma descarga completa e total, através dos neurônios motores), sofrerá uma importante modificação. Com efeito, com essa sua conformação, tal sistema só se encontra adaptado para responder aos estímulos que vêm de fora. E nós sabemos que esse sistema também recebe estímulos que provêm do interior do corpo ou "estímulos endógenos", que "se originam nas células do organismo e criam as grandes necessidades: fome, respiração, sexualidade" (1966, v. I, p. 296-7; 1950, p. 306). Esses estímulos precisam ser apaziguados, porque sua não-satisfação gerará desprazer; para tanto far-se-á necessário efetivar, no mundo externo, uma série de condições, o que vai requerer a intervenção de uma ação que Freud chamará de "específica" (1966, v. I, p. 297; 1950, p. 306). Mas para se realizar tal "ação" (que pressupõe a interação entre o sistema, seu meio ambiente, e um outro ser humano, cuja percepção será de capital importância para a configuração em " $\Psi$ " de circuitos representativos que estarão na base de processos cogitativos e cognitivos, e também para a emergência da ordem moral no sistema), o sistema deverá contar com uma espécie de "reserva energética", cuja origem estaria justamente nessas "Qs" que os estímulos endógenos vão acumulando em " $\Psi$ do núcleo", conforme foi exposto. 
Assim, o sistema "... vê-se obrigado a abandonar sua tendência inicial à inércia (isto é, a reduzir o nível [da On'] a zero)" (1966, v. I, p. 297; 1950, p. 306).

E aqui terá lugar a modificação do mencionado princípio, o que não implicará, todavia, sua supressão, já que mesmo a maneira em que o sistema abandonaria sua tendência à inércia, "demonstra que a mesma tendência persiste, modificada pelo empenho de ao menos manter a On' no mais baixo nível possível e de se resguardar contra qualquer aumento da mesma - ou seja, mantê-la constante" (1966, v. I, p. 297; 1950, p. 306-7). Freud acaba de enunciar uma versão daquilo que será formulado bem mais tarde com o nome de "princípio de constância" (1955b, v. XVIII, p. 9).

Portanto, o "princípio de constância" será o encarregado de "administrar" as quantidades em jogo no sistema de tal modo que este possa, na medida do possível, se ver livre das mesmas (inércia), mas dando conta, ao mesmo tempo, das exigências que são colocadas pela pressão dos estímulos endógenos, exigências essas que são da ordem do organísmico ou vital.

\section{O estatuto do psicológico}

Temos exposto o que, conforme nosso ponto de vista, teriam sido as estratégias de modelização do psiquismo que o "Projeto" empregara na sua tentativa de "apresentação" dos processos psicológicos em termos de quantidades e neurônios.

Uma vez delineado também o estatuto dos componentes básicos do modelo em apreço, e havendo-se apontado o princípio operacional do mesmo, vejamos que tipo de assimilação esse modelo teria promovido entre o duplo domínio secundário e o domínio original que foram postos em correlação, isto é, entre o domínio do neuronal e do psicopatológico, por um lado, e o dos processos psicológicos em geral, pelo outro. ${ }^{12}$

a) Através do elemento "quantidade", e via esse atributo do quantitativo que fora destacado como sendo essencial, a fluência, o modelo teria assimilado os domínios em consideração, de sorte que os processos psicológicos poderiam, por sua vez, ser concebidos enquanto perpassados por "uma quantidade em estado fluente". Mas isto significa que o elemento quantitativo está se comportando, nas ordens processuais do neurológico e do psicológico, de uma maneira idêntica (a "O" flui), mesmo que não se saiba, a rigor, se se trata de uma "O" da mesma natureza agindo nos dois casos. Todavia, uma tal quantidade poderia ${ }^{13}$ ver-se "qualitizada", por assim dizer, nos processos psicológicos, por uma certa coloração afetiva, o que erigir-se-ia como um elemento de caráter diferencial.

12. Não tematizaremos aqui a questão das identidades e diferenças existentes entre os processos psicopatológicos e os processos psicológicos "normais". Consideraremos os processos psicológicos em geral, mas deixando registrado o fato de que, para Freud, a diferença entre ambos os tipos de processos é mais de grau do que de essência, e determinada, em última instância, por fatores de tipo quantitativo.

13. Dizemos "poderia" porque a quantidade em questão é, a princípio, e em si mesma, apenas uma quantidade de investimento. Ver, a esse respeito, Green, 1983, p. 19). 
Há ainda um outro aspecto implicado pela assimilação em questão. O fato de essa quantidade em estado fluente ser a forma assumida pela excitação neuronal nos autorizaria a inferir que a soma de excitação que está em circulação tanto nos processos psicológicos quanto nos processos neuronais encontra-se regulada pelo mesmo princípio, ou "princípio de constância", isto é, a tendência a manter um nível mínimo de " $\mathrm{Q}$ " em funcionamento (ou pelo menos a mantê-la constante). Assim (e considerando também o comportamento fluente da " $\mathrm{Q}$ "), poderíamos afirmar que haveria uma espécie de identidade funcional, do ponto de vista quantitativo/energético, entre os processos psicológicos e os neuronais.

Ainda considerando o fator quantitativo-energético, devemos relembrar que o "Projeto" assentara, como uma de suas teses, que a quantidade que penetrava em " $\Psi$ " a partir de elementos somáticos (do interior do corpo) erigia-se em fator de impulsão de toda a atividade psíquica.

Partindo desta colocação, é possível concluir que, do ponto de vista da "força que alimenta", por assim dizer, tanto os processos psicológicos quanto os processos neuronais teriam como manancial a mesma fonte de "energia". ${ }^{14} \mathrm{E}$ embora uma tal "energia" não fique definida, pensamos que ela é, em todo caso, dados os elementos com que contamos, da ordem do biológico no sentido do organísmico ou vital.

b) Através do elemento "neurônio", e pelo viés da "colagem" do elemento "representação", nos termos em que a coisa foi colocada por nós, isto é, a partir de pressupostos brentanianos que teriam sido apropriados por Freud, a assimilação que o modelo teria promovido entre os processos neuronais e os psicológicos seria algo do seguinte tipo: o neuronal constituiria uma espécie de ponto ou lugar do qual emergeria - de uma maneira que se ignora - esse "apontar para algo" (para um conteúdo ou um objeto) que é o que caracteriza a dimensão do propriamente intencional ou psicológico, de sorte que os processos psicológicos poderiam ser vistos como emergentes do neuronal e na qualidade de intencionais. Pensamos que os neurônios não apontam para nada, no sentido intencional, claro está, mas algo, em seu comportamento, parece permitir que esse apontar se dê. Assim, para dar um exemplo, sabemos que o representar implica intencionalidade, é um apontar virtual para algo; mas, para que isto aconteça, é necessário (não sabemos se também suficiente - o que significa que suspenderemos o juízo a respeito da questão da causação) que as representações que estão registradas no sistema " $\Psi$ " sob a forma de traços de memória sejam ativadas ou investidas. Isto é, os neurônios " $\Psi$ ", que são seus "portadores", devem ser ocupados por " $\mathrm{Q}$ ".

Os resultados que acabamos de expor, malgrado seu teor conjectural, posto que eles se assentam, afinal, em alguns pressupostos filosóficos que teriam passado para Freud através de Brentano, encontram, todavia, bons apoios no texto do "Projeto". Vamos nos remeter a um desses apoios, talvez o principal. Ao abordar a emergência

14. Algo assim como um fator de excitabilidade, diriamos nós. Ao usarmos a palavra "energia" estamos, a rigor, fazendo uso de uma licença verbal, posto que tal palavra não faz parte do vocabulário técnico do "Projeto". 
do desejo (Wunsch) no aparelho, Freud conceitua o mesmo em termos de "atração" ou movimento que, partindo da situação de desprazer gerada pela acumulação de Qn" em " $\Psi$ " do núcleo (via a estimulação endógena), investirá - e isto de um modo puramente mecânico, quanto à circulação de On' - a representação do objeto desejado, objeto esse que se encontra associado à desaparição do desprazer. Que estatuto outorgar, todavia, a uma tal representação? Em termos de quantidades e neurônios, e atendendo ao processo de sua constituição, a referida representação não é nada mais do que um traço de memória deixado em " $\Psi$ " do pallium pela $\mathrm{Q}$ introduzida por uma percepção que estivera ligada a uma "vivência": a da satisfação de uma necessidade ou carência que " $\Psi$ " experimentara. (Isto explica por que a representação de desejo, "herdeira" dessa percepção, encontra-se associada à desaparição de desprazer.) (Freud, 1966, v. I, p. 317-9, 321-2; 1950, p. 325-7, 329; Milidoni, 1993, p. 116-22). Ora, pensamos nós, o investimento desse traço de memória implicará também a intervenção de atos intencionais, posto que o investimento de desejo é investimento daquilo que o desejo deseja, por assim dizer, do seu objeto intencional, e este ato intencional do desejo está naturalmente intermediado pelo ato, também intencional, que vem representar um tal objeto, tornando-o presente na forma de uma imagem ou idéia. (Freud fala da "imagem mnêmica do objeto".) (1966, v. I, p. 319; 1950, p. 327).

As conclusões aqui expostas foram elaboradas com base em uma maneira de interpretar a função do modelo do psiquismo proposto pelo "Projeto". Essa interpretação baseia-se - como já foi dito - em pressupostos epistemológicos oriundos do pensamento de Black (1966b, p. 222-5), pressupostos estes que conferem um privilégio ao que tal autor chama de "uso existencial" de modelos teóricos, o qual pressupõe, por outro lado, a forma de operar por assimilação ou identificação de domínios que é própria das metáforas interativas. Via tal "uso existencial", o modelo pretende apreender as entidades que estão sendo visadas "tal como elas são", opondo-se assim a um uso que só conferiria a esses modelos o estatuto de ficções heurísticas.

Pensamos que o modelo do "Projeto" comportaria um uso de tipo "existencial", embora não sem certas restrições. Com efeito, a índole metapsicológica do construto facultaria o mesmo para capturar a realidade que está sendo visada de uma maneira que é somente aproximativa. Talvez seja por isso - entre outras razões - que o "Projeto" apresenta oscilações quanto ao uso que faz do construto em apreço, indo de um uso decididamente "realístico", para outro meramente figurativo ou "fictício". A despeito de tais oscilações, pensamos que o modelo do "Projeto" fornece pelo menos indícios a respeito do modo de ser próprio daquilo que está sendo "apresentado", isto é, dos processos psicológicos.

Tendo como ponto de apoio este conjunto de ponderações, nos sentimos encorajados para tecer agora, finalmente, algumas considerações que têm a ver com o estatuto ou a natureza do psicológico em termos do "Projeto", o que faremos dando primeiramente uma forma esquemática àquelas conseqüências que nossa interpretação em torno do estatuto e função do modelo em questão nos permitiu extrair. 
Conforme, pois, essa interpretação, caberia dizer que, no "Projeto", o psicológico qualifica processos que são em si distintos dos processos da ordem do neurofisiológico, mas que mantêm com estes relações ou pontos de contato que são determinantes em termos de sua configuração.

Com base nesses pontos de contato ou dessas relações, podemos oferecer a seguinte caracterização dos processos psicológicos:

1. Trata-se de processos que, do ponto de vista quantitativo-energético apresentam uma identidade funcional com os processos neurofisiológicos.

2. Trata-se de processos cujas condições de ocorrência estão no plano do neurofisiológico. É a partir daí que eles emergem com sua característica distintiva, isto é, a intencionalidade. Todavia, esses processos pressupõem a interação dinâmica com o meio ambiente e os outros seres humanos, pela via da ação (que tem o seu modelo na ação que foi chamada de "específica"). Isto significa que a emergência do psicológico não se dá a partir do neurofisiológico como esfera processual isolada.

3. Trata-se de processos que compartilham, com os processos neurofisiológicos, a mesma fonte energética, que é da natureza do organísmico ou vital. Estes seriam, conforme nosso entender, os pontos de destaque. Pode seguramente parecer estranho que nada tinha sido dito a respeito do elemento "consciência". Sem entrar em detalhes - posto que se trata de um assunto que merece um tratamento à parte - podemos apontar aqui o que julgamos ser a tese central do "Projeto" a esse respeito: o elemento "consciência" é um agregado de qualquer processo " $\Psi$ ", o que significa que ele pode faltar. Como se entende isto?

Sabemos que os neurônios encarregados de "veicular" a consciência são os neurônios perceptivos, os " $\omega$ ". Mas se bem toda percepção implica consciência, isto é, a conciência de uma qualidade (seja esta qualidade de tipo sensorial, seja afetiva ou intensiva - como é a própria das sensações de prazer/desprazer - seja, por assim dizer, verbal - aquela que está associada às sensações visuais, auditivas e motrizes da fala, e que é responsável pela conscientização de representações), há processos que ocorrem sem consciência, como é o caso de certos processos de pensamento (Freud 1966, v. I, p. 373; 1950, p. 371-2).

A consciência, no marco do "Projeto", não é pois uma característica que se encontre associada, de forma permanente, a qualquer ocorrência no plano psicológico. Ela acompanha sempre a percepção, mas pode acompanhar ou não um processo puramente representacional, isto é, que ocorre só em " $\Psi$ " (feita a ressalva de que, ainda nesse caso, haverá esporádicas conscientizações de alguns dos elos desse processo).

Esta falta de equacionamento entre "psíquico" e "consciente", e a primazia que é dada no "Projeto" ao sistema " $\Psi$ " (o sistema mnemônico/representacional) nos induz a acrescentar mais um item àqueles que temos arrolado acima.

Assim, teríamos, finalmente:

4. Os processos psicológicos são, essencialmente, processos representacionais que têm sua base em um sistema neurônico privilegiado, o " $\Psi$ ". (Não esqueçamos, 
aqui, que as representações envolvidas são, antes de mais nada, traços mnésicos desprovidos de qualidade e, portanto, de consciência, e que o representar que emergeria com a sua ativação seria possuidor de uma espécie de intencionalidade sem consciência).

Sintetizando, pois, o que foi exposto a respeito do estatuto do psicológico no "Projeto", diremos que o psicológico é aquilo que emerge do neurofisiológico na qualidade do intencional/representacional, configurando uma categoria ontologicamente distinta de processos, mas que é, ao mesmo tempo, aquilo que funciona, do ponto de vista quantitativo-energético, de uma maneira idêntica ao neurofisiológico.

Se quisermos encaixar tal tipo de conceituação dentro das posições mais extremas que em termos de "dualismo" ou de "monismo" se colocam com relação ao clássico problema mente-corpo (ou psíquico-neuronal), haveremos, certamente, de ter dificuldades que nos parecem ser insuperáveis.

Pois a conceituação apontada não casaria bem nem com a posição dualista clássica, isto é, a cartesiana, que sustenta um dualismo mente-corpo de tipo substancial (Descartes, 1979 - Medit. 6a), nem tampouco com uma posição monista que, em sua versão fisicalista radical, postulasse a existência de uma identidade de caráter empírico entre cérebro e mente, como é a posição defendida, entre outros, por Smart (1965, cap. 5).

Haveria, no enfoque freudiano do "Projeto", uma espécie de dualismo; mas este não seria substancial, posto que o psicológico é distinto mas não autônomo com relação ao neurofisiológico; e haveria, também, ao mesmo tempo, uma espécie de monismo, que seria de tipo funcional e seria implicado pelo comportamento do fator quantitativo-energético. ${ }^{15}$

Talvez tenhamos que buscar novos rótulos.

MILIDONI, C. B. Some considerations on the status of the psychic in "Freudian Project". Trans/Form/Ação, v. 17, p. 151-166, 1994.

- ABSTRACT: Although Freud's "Project" does not contain overt formulations concerning the nature of the psychic, we think that it is possible to sketch some of its essential traits. To do so, we shall interpret the model of the mind constructed in the "Project". From this, we shall proceed to put the "Project" views on the nature of the psychic in connection with the classic mind-body problem. Our account will rest especially on a distinction we shall make between "representing", seen as an intentional act, and "the representation", seen as a memorytrace. We shall also consider the behaviour of the quantitativeenergetic factor in both the psychological and neuro-physiological process orders.

- KEYWORDS: Neurone; quantity; fluency; memory-trace; representation; intentionality; functional identity.

15. Seria interessante, pensamos, cotejar esta posição com as ponderações vertidas por E. Jones a respeito da relação mente-cérebro em Freud. Ver Jones, 1979, p. 379-81. 


\section{Referências bibliográficas}

1 BLACK, M. La metáfora. In: Modelos y metáforas. Trad. V. Sanchez de Zavala. Madrid: Tecnos, 1966 a. p. 36-56, (Estrutura y Función, 23).

2 Modelos y arquetipos. In: . Modelos y metáforas. Trad. V. Sanchez de Zavala, Madrid: Tecnos, 1966 b. p. 216-38. (Estrutura y Función, 23).

3 BREnTANO, F. Psychologie du point de vue empinique. Trad. M. Gandillac. Paris: Aubier-Montaigne, 1944.

4 COMTE, A. Cours de philosophie positive. Paris: Hermann, 1975.

5 DESCARTES, R. Meditações. Trad. J. Guinsburg e B. Prado Jr. São Paulo: Abril Cultural, 1979.

6 FREUD, S. Entwurf einer Psychologie. In: Aus den Anfängen der Psychoanalyse. London: Imago, 1950.

7 . The neuro-psychoses of defence. In: The standard edition of the complete psychological works of Sigmund Freud. Trad. J. Strachey. London: Hogarth, 1955 a. v. III, p. 45-61.

8 . Beyoud the pleasure principle. In: The standard edition of the complete psychological works of Sigmund Freud. Trad. J. Strachey. London: Hogarth, 1955 b. v. XVIII.

9 . Some elementary lessons in psychoanalysis. In: The standard edition of the complete psychological works of Sigmund Freud. Trad. J. Strachey. London: Hogarth, 1964. v. XXIII.

10 . Project for a scientific psychology. In: The standard edition of the complete psychological works of Sigmund Freud. Trad. J. Strachey. London: Hogarth , 1966. v. I.

11 . Instincts and their vicissitudes. In: The standard edition of the complete psychological works of Sigmund Freud. Trad. J. Strachey. London: Hogarth, 1967. v. XIV, p. 169-94.

12 GREEN, A. O discurso vivo - uma teoria psicanalítica do afeto. Trad. R. J. Dias. Rio de Janeiro: Ed. F. Alves, 1982.

13 JONES, E. Vida y obra de Sigmund Freud. Trad. M. Carlinsky. Buenos Aires: Ed. Hormé, 1979. v. I.

14 LAPLANCHE, J. Dérivation des entités psychanalytiques. In: Vie et mort en Psycanalyse. Paris: Flammarion, 1970. p. 197-214.

15 MILIDONI, C. B. Heurística freudiana no "Projeto para uma psicologia científica". Campinas, 1993. 329 p. Tese (Doutorado em Lógica e Epistemologia) - Instituto de Filosofia e Ciências Humanas, Universidade Estadual de Campinas.

16 MONZANI, L. R. Freud: o movimento de um pensamento. Campinas: UNICAMP, 1989.

17 SEARLE, J. Mente, cerébro e ciência. Trad. A. Morão. Lisboa: Edições 70, 1987. (Biblioteca de Filosofia Contemporânea).

18 SMART, J. J. C. Philosophy and scientific realism. London: Routledge \& K. Paul, 1965.

19 WOLlHEIM, R. As idéias de Freud. Trad. A. Cabral. São Paulo: Cultrix, s.d. 